\title{
Familial cerebellar ataxia with cerebrovascular amyloid
}

\author{
S LOVE, LW DUCHEN
}

From the Department of Neuropathology, Institute of Neurology, The National Hospital, Queen Square, London

SUMMARY We report a rare association of familial cerebellar ataxia (without dementia) and cerebrovascular amyloid. Postmortem neuropathological examination of one member of the family showed amyloid angiopathy of the central nervous system with heavy infiltration of capillaries in the hippocampus and cerebellum.

Cerebrovascular amyloid occurs in a number of clinical contexts and may be an asymptomatic finding in the elderly. ${ }^{1}$ Patients may develop dementia and the risk of cerebrovascular accidents is increased..$^{2}$ There are known associations of amyloid angiopathy with Alzheimer's disease ${ }^{3}$ and spongiform encephalopathy. ${ }^{4}$ To our knowledge, cerebellar ataxia with cerebrovascular amyloid has previously been reported in only one family in which affected members became demented early in the course of the illness. ${ }^{5}{ }^{6}$ The present report is of cerebrovascular amyloid affecting one member of a family in which four members in three successive generations developed cerebellar ataxia without dementia.

\section{Case report}

Mrs IB, a 49-year-old housewife, presented with slight unsteadiness of gait. She gave no history of alcohol ingestion, exposure to carbon monoxide, previous head injury or encephalitis, and was taking no medication. Her maternal grandfather had been bedridden with "unsteady limbs" for 9 years prior to his death. One maternal uncle died following a cerebral haemorrhage, and two maternal uncles suffered from cerebellar ataxia with nystagmus. Eleven other maternal aunts and uncles as well as the patient's mother died from unrelated illnesses. Two siblings are believed to be healthy.

Address for reprint requests: Dr S Love, Department of Neuropathology, Institute of Neurology, The National Hospital, Queen Square, London WC1N 3BG, UK.

Received 24 September 1981 and in revised form 11 November 1981

Accepted 18 November 1981
Examination disclosed mild, symmetrical cerebellar ataxia of the limbs and trunk with a slurring dysarthria and nystagmus on lateral gaze. The blood pressure was $120 / 70 \mathrm{~mm} \mathrm{Hg}$ while lying supine. Haematological and biochemical investigations, including thyroid function tests, were normal. No abnormalities were noted on chest, skull and cervical spine radiographs. A Wasserman test was negative. The ataxia worsened progressively so that within two years she could not walk without support. Three years after her first presentation she developed sudden weakness and stiffness of the left lower limb. Tone was increased in that limb, with left ankle clonus and bilateral extensor plantar responses. Sensation was intact. An electroencephalogram was diffusely abnormal; irregular, intermittent $11 \mathrm{~Hz}$ alpha rhythm was present with a left-sided emphasis and irregular $15 \mathrm{~Hz}$ activity occurred with a right-sided emphasis. A brain scan was normal. Progressive incapacitation led to her admission to a home for the physically handicapped. During her last few months of life she became incontinent of urine and, for the first time, impairment of memory for recent events was noted, although she remained orientated and lucid. She died ten years after the onset of her illness, at the age of 59 years.

Neuropathological findings Consent was obtained for a post mortem examination limited to the central nervous system. The external appearance of the brain and spinal cord was normal. The unfixed brain weighed $1240 \mathrm{~g}$. After fixation the cerebrum was sectioned coronally. The lateral and third ventricles were slightly dilated. Two slit-like, small infarcts were present in the white matter of the right frontal and temporal lobes. No abnormalities were seen in the brain stem, cerebellum or spinal cord. Blocks were taken from many areas of the cerebral hemispheres, brain stem, cerebellum and spinal cord. In the cerebral hemispheres and leptomeninges, arteries 
and arterioles were diffusely thickened by eosinophilic, acellular material with affinity for Congo red and showing yellow-green birefringence under polarised light thus fulfilling the criteria for amyloid. ${ }^{7}$ In many areas the lumen was narrowed and in places amorphous deposits of amyloid extended for short distances into the surrounding brain parenchyma. Scanty deposits were present in the tunica media of some veins. Involvement of capillaries was virtually restricted to the hippocampal formation where amyloid infiltrated capillary walls, occasionally occluding the lumen, and radiating spicules of amyloid extended into the surrounding parenchyma. These deposits were not argyrophilic with either the Glees and Marsland or Palmgren method of silver impregnation. In addition, numerous neuritic (senile-type) plaques were present in the dentate fascia, hippocampal formation and subiculum but nowhere else in the cortex, and many hippocampal pyramidal cells contained neurofibrillary tangles or granulovacuolar inclusions. The presence of old infarcts in the white matter was confirmed. The basal ganglia and brain stem showed widespread arterial amyloid, capillaries being spared.

The cerebellum was extensively infiltrated by large deposits of amyloid, many of which were clearly related to capillaries (fig 1). These deposits were numerous in the molecular and granule cell layers and a few were present in the white matter. Generalised arterial amyloid was present in the cerebellum and overlying leptomeninges. There was severe depletion of Purkinje cells and many "torpedoes" were noted on axons of those surviving (fig 2). The granule cells were relatively well preserved. The molecular layer showed Bergmann cell hyperplasia and there was nerve fibre loss and gliosis in the white matter. Arterial amyloid was present throughout the spinal cord and in the spinal leptomeninges with only occasional capillary involvement in the white matter. There was a rim of nerve fibre loss in the subpial white matter of the cervical region. The nerve roots showed no vascular amyloid and no other pathological abnormalities.

\section{Discussion}

Worster-Drought, Greenfield and McMenemey described a family with presenile dementia, spastic paraplegia, ataxia of gait and nystagmus. ${ }^{56}$ Postmortem examination of two members showed generalised "hyaline" arterial wall thickening and argyrophilic pericapillary deposits (later confirmed to be amyloid) most numerous in the hippocampal formation and cerebellum, but also involving the pons and medulla. Neuritic plaques and neurofibrillary tangles were present in the hippocampal cortex, and the cerebellum showed some loss of Purkinje cells with "torpedoes" on axons of surviving cells. Their case, unlike the present one, showed widespread white matter degeneration and gliosis. Although atypical "kuru" plaques have been described in other progressive neurological diseases

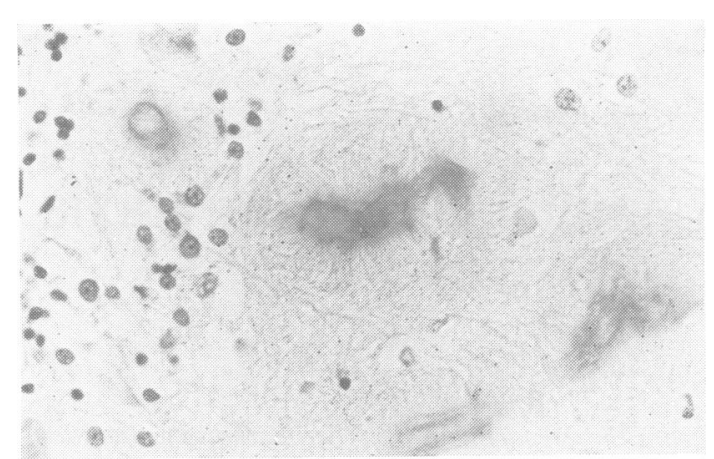

Fig 1 Section shows cerebellar molecular layer. Capillaries are infiltrated by amyloid which extends as spicules into surrounding neuropil. Congo red-haematoxylin $\times 290$.

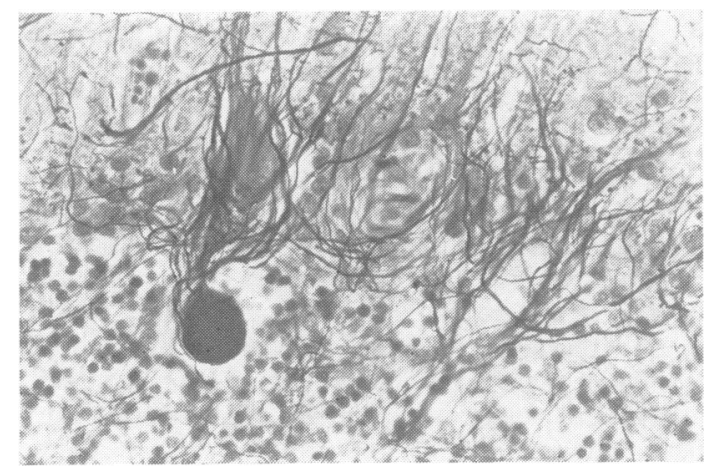

Fig 2 Section shows cerebellar Purkinje cell layer. A torpedo is present on the axon of a degenerating Purkinje cell. There is also evidence of Purkinje cell loss. Glees and Marsland silver impregnation $\times 270$.

with cerebellar ataxia, ${ }^{910}$ vascular amyloid has not been present.

In the family described by Worster-Drought $e t$ al, dementia was a prominent feature. This may reflect the extensive white matter changes and, possibly, more severe hippocampal damage. The patient reported here remained lucid and alert until her death, and no other family members became demented. However, ataxia of gait and nystagmus were common to both families, with almost identical appearance and distribution of the cerebrovascular amyloid. Familial cerebellar ataxia, with or without dementia, appears, therefore, to be a further manifestation of cerebrovascular amyloid, which is associated with microvascular amyloid in the hippocampus and cerebellum. 


\section{References}

${ }^{1}$ Wright JR, Calkins E, Breen WJ, Stolte G, Schultz RT. Relationship of amyloid to aging. Review of the literature and systematic study of 83 patients derived from a general hospital population. Medicine (Baltimore) 1969;48:39-60.

2 Okazaki H, Reagan TJ, Campbell RJ. Clinicopathologic studies of primary cerebral amyloid angiopathy. Mayo Clin Proc 1979;54:22-31.

${ }^{3}$ Mandybur TI. The incidence of cerebral amyloid angiopathy in Alzheimer's disease. Neurology $(N Y)$ $1975 ; 25: 120-6$.

4 Adam J, Crow TJ, Duchen LW, Scaravilli F, Spokes E. Familial cerebral amyloidosis and spongiform encephalopathy.J Neurol Neurosurg Psychiatry 1982; $45: 237-245$.

5 Worster-Drought C, Greenfield JG, McMenemey WH. A form of familial presenile dementia with spastic paralysis (including the pathological examination of a case). Brain 1940;63:237-54.

${ }^{6}$ Worster-Drought C, Greenfield JG, McMenemey WH. A form of familial presenile dementia with spastic paralysis. Brain 1944;67:38-43.

- Cooper JH. Selective amyloid staining as a function of amyloid composition and structure. Lab Invest $1974 ; 31: 232-8$.

${ }^{8}$ Glenner GG, Eanes ED, Bladen HA, Linke RP, Termine JD. $\beta$-pleated sheet fibrils. A comparison of native amyloid with synthetic protein fibrils. $J$ Histochem Cytochem 1974;22:1141-58.

${ }^{9}$ Gerstmann J, Sträussler E, Sheinker I. Über eine eigenartige hereditär-familiäre Erkrankung des Zentralnervensystems. gesamte Neurol Psychiatr 1936;154:736-62.

${ }^{10}$ Boellaard JW, Schlote W. Subakute spongiforme Encephalopathie mit multiformer Plaquebildung. Acta Neuropathol 1980;49:205-12. 